\title{
Strawberry-flavored yogurts and whey beverages: What is the sensory profile of the ideal product?
}

\author{
D. R. Janiaski, ${ }^{*}$ T. C. Pimentel, $†$ A. G. Cruz, $\ddagger$ and S. H. Prudencio*1 \\ *Universidade Estadual de Londrina (UEL), Departamento de Ciência e Tecnologia de Alimentos (DCTA), Londrina, Paraná, 86051-970, Brazil \\ †Instituto Federal do Paraná (IFPR) - Campus Paranavaí, Rua José Felipe Tequinha, 1400, Jardim das Nações, Paranavaí, Paraná, \\ 87703-536, Brazil \\ †Instituto Federal do Rio de Janeiro (IFRJ) - Campus Maracanã, Mestrado Profissional em Ciência e Tecnologia de Alimentos (PGCTA), \\ Rua Senador Furtado, 171, Maracanã, 20270-021, Rio de Janeiro, Brazil
}

\begin{abstract}
This study aimed to evaluate the sensory profile and Brazilian consumers' liking of strawberry-flavored yogurts and whey beverages (fermented or nonfermented) with different fat contents that were sweetened with sugar or nonsugar sweeteners. We also determined the influence of sensory attributes on consumer preferences and the profile of the ideal product. Nonfermented whey beverages (NFWB) and "light" yogurt were less liked. The NFWB were less acidic, less viscous, and with lower smoothness of mouthcoating, sweeter and with a more intense artificial strawberry aroma (ASA) than the fermented products. Low-fat yogurts were more liked, more viscous, and had higher smoothness of mouthcoating than nonfat yogurts. Fermentedwhey beverages were as liked as yogurts. Viscosity and smoothness of mouthcoating positively influenced consumer liking. The ideal product had higher levels of brightness, artificial strawberry taste, artificial strawberry aroma, and sweet taste; intermediate smoothness of mouthcoating, color, and viscosity; and low particles, acid taste, and aroma.
\end{abstract}

Key words: whey, sensory, yogurt, fat, whey beverage

\section{INTRODUCTION}

Whey beverages are fermented or nonfermented products in which whey is used as an ingredient (Gomes et al., 2013). These products need to have a $51 \%$ milk base minimum in the formulation and the use of vegetable fat is allowed (Brasil, 2005). Yogurts are fermented milk products in which the dairy ingredients must be greater than $70 \%$, the addition of vegetable fat

Received July 10, 2015.

Accepted November 19, 2015.

${ }^{1}$ Corresponding author: sandrah@uel.br is not allowed, and whey is not a mandatory ingredient; therefore, yogurts may be produced with or without whey (Brasil, 2007).

From a technological point of view, the primary difference between fermented whey beverages and yogurts with added whey is the form in which the whey is added. In fermented whey beverages, liquid or reconstituted whey is always used, whereas in yogurts, whey protein concentrates (WPC) are preferred. Using WPC instead of skim milk powder results in a cost reduction in yogurts (Hugunin, 2009; Castro et al., 2013). In turn, nonfermented whey beverages (NFWB) are products in which milk does not undergo fermentation and commercial sterilization is applied as heat treatment; therefore, these products do not require refrigerated storage and they may be transported and consumed in places where the cold chain cannot be maintained (Pelegrine and Carrasqueira, 2008).

The consumption of whey beverages and yogurts is growing around the world (Legarová and Kourimská, 2010; Castro et al., 2013; Boynton and Novakovic, 2014). In Brazil, $50 \%$ of the population consumes whey beverages, mostly for breakfast (News and Trends, 2011 ), and $74 \%$ of the population consumes yogurt (Silvestrini, 2013). These dairy products have been evaluated for their benefits to consumer health (Lollo et al., 2013).

In recent decades, consumers have increased awareness about health and quality of life, which has encouraged people to exercise, adopt healthy eating habits, and reduce their consumption of foods high in sugar, salt, and fat (Pinheiro et al., 2005). Replacing sugar with nonsugar sweeteners in dairy products can change their sensory profile (Esmerino et al., 2013; Paixão et al., 2014), and a reduced fat content can cause defects in products, such as a loss of taste and lack of consistency or texture (Guven et al., 2005; Pimentel et al., 2012).

Studies assessing the sensory profile and consumer acceptance of yogurts and whey beverages have been 
published around the world (Salvador and Fiszman, 2004; Thompson et al., 2007; Lovely and Meullenet, 2009; Cruz et al., 2013; Silva et al., 2013). However, these studies did not evaluate sensory attributes of yogurts and whey beverages with different fat contents and different sweeteners, and differences may exist in sensory attributes among these products that are important for consumer liking. Additionally, because of the similarity in processing steps for the 2 types of products, it would be interesting to understand the sensory attributes that characterize the affective ideal product, which could be used to create an optimized formulation for a greater probability of success with consumers (Ares et al., 2011).

The aim of this study was to establish sensory profiles, Brazilian consumers' liking, and the attributes that most influenced consumer preferences of yogurts and whey beverages (fermented or nonfermented) with different fat contents that were sweetened with sugar or nonsugar sweeteners. Additionally, the sensory profile of the ideal product was projected.

\section{MATERIALS AND METHODS}

We evaluated 8 strawberry-flavored dairy products that were sold in Brazil. They consisted of 4 yogurts: 2 nonfat (YOG1 and YOG3) and 2 low fat (YOG2 and YOG4); 2 low-fat fermented whey beverages (WB3 and WB4), and 2 nonfermented whey beverages, 1 full fat (WB1) and 1 low fat (WB2). The YOG3 yogurt was sweetened with artificial sweeteners (sodium cyclamate, $51.5 \mathrm{mg} / 100 \mathrm{~g}$, and aspartame, $29.2 \mathrm{mg} / 100 \mathrm{~g}$ ), and the other products were sweetened with sucrose.

Strawberry flavor was chosen because it represents the largest number of products available in the Brazilian market and the greatest consumer preference (Allgeyer et al., 2010; Ribeiro et al., 2010; Cassell, 2014). The evaluated products are described in Table 1, and their

Table 1. A description of the samples according to the manufacturer

\begin{tabular}{|c|c|c|c|}
\hline Product & Type & Fat content & Ingredients \\
\hline YOG2 & Yogurt & Low fat & $\begin{array}{l}\text { Full-fat milk or full-fat reconstituted milk, strawberry preparation } \\
\text { (water, sugar, strawberry pulp, modified starch, natural carmine coloring, } \\
\text { strawberry aroma identical to natural and preservative potassium sorbate), } \\
\text { milk protein concentrate and whey milk protein concentrate, lactic culture, } \\
\text { and citrus pectin and guar gum thickeners }\end{array}$ \\
\hline YOG3 & Yogurt & Nonfat & $\begin{array}{l}\text { Full-fat milk or full-fat reconstituted milk, strawberry preparation [water, } \\
\text { strawberry pulp, vitamins, artificial sweeteners sodium cyclamate ( } 51.5 \\
\mathrm{mg} / 100 \mathrm{~g}) \text { and aspartame }(29.2 \mathrm{mg} / 100 \mathrm{~g}) \text {, natural carmine coloring, } \\
\text { strawberry aroma identical to natural, guar gum thickener and potassium } \\
\text { sorbate preservative], pectin stabilizer and starter cultures }\end{array}$ \\
\hline YOG4 & Yogurt & Low fat & $\begin{array}{l}\text { Standardized milk or reconstituted milk, whey, sugar, strawberry } \\
\text { preparation (inverted sugar, strawberry pulp, water, modified starch } \\
\text { stabilizer, strawberry flavor identical to natural, artificial coloring } \\
\text { Bordeaux-5, potassium sorbate preservative and citrus pectin stabilizer), } \\
\text { gelatin powder stabilizer, natural carmine coloring, Red Ponceau (4R) } \\
\text { artificial coloring and dairy cultures }\end{array}$ \\
\hline WB2 & Whey beverage & Low fat & $\begin{array}{l}\text { Full-fat milk or full-fat reconstituted milk, whey, sugar, water, maltodextrin, } \\
\text { strawberry-flavored food compound, vitamins }\left(\mathrm{A}, \mathrm{B}_{1}, \mathrm{~B}_{2}, \mathrm{~B}_{6}, \mathrm{C}, \mathrm{E} \text {, and }\right. \\
\text { niacin), salt, flavoring, natural carmine coloring, sodium citrate stabilizer } \\
\text { and potassium hydroxide and sodium hydroxide acid regulators }\end{array}$ \\
\hline WB3 & Fermented whey beverage & Low fat & $\begin{array}{l}\text { Low-fat milk or partially reconstituted nonfat milk, sugar syrup, modified } \\
\text { starch, strawberry preparation (sugar, water, strawberry pulp, citric acid, } \\
\text { flavoring, potassium sorbate preservative and Red Ponceau and brilliant } \\
\text { blue artificial coloring), reconstituted whey, lactic culture and citric acid }\end{array}$ \\
\hline WB4 & Fermented whey beverage & Low fat & $\begin{array}{l}\text { Full-fat reconstituted milk, fruit preparation (water, sugar syrup, modified } \\
\text { starch, sugar, strawberry pulp, tricalcium phosphate, powdered whey, citric } \\
\text { acid, flavoring, xanthan gum thickener, natural carmine coloring and sorbate } \\
\text { potassium preservative) and lactic culture }\end{array}$ \\
\hline
\end{tabular}




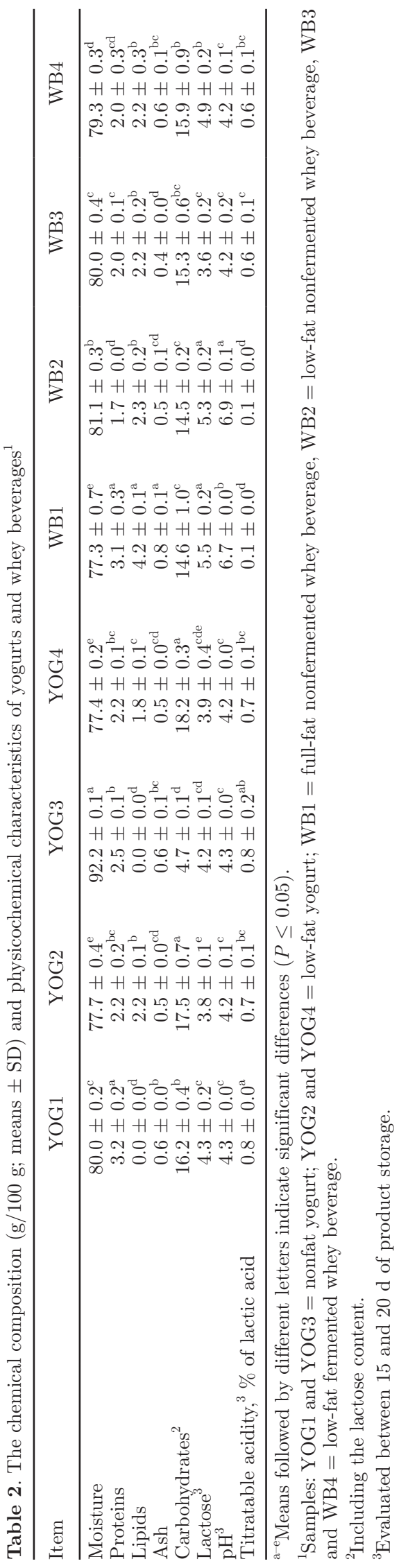

chemical composition and physicochemical properties are shown in Table 2.

\section{Physicochemical Analysis}

The $\mathrm{pH}$, titratable acidity, and lactose contents were determined between 15 and $20 \mathrm{~d}$ from the date of manufacture printed on the packaging of the products. The samples were bought in the first week of manufacture and stored at $4^{\circ} \mathrm{C}$ until analysis; therefore, storage temperature did not influence the results. Three samples were used for each product evaluated, all of which belonged to the same batch, and the analysis were done in triplicate. Moisture, protein, fat, ash, carbohydrate, lactose, $\mathrm{pH}$, and titratable acidity measurements were performed according to AOAC International (2004) methods.

The light yogurt YOG3 presented the highest moisture content, because of the absence of sugar to contribute to the total solids. The products with addition of milk powder (YOG1 and WB1) had the highest protein contents, whereas the low-fat yogurts (YOG2 and YOG4) presented higher contents of carbohydrates. As expected, nonfat yogurts (YOG1 and YOG3) had no lipids, the full-fat nonfermented whey beverage, WB1, had the highest lipid content $(4.2 \mathrm{~g} / 100 \mathrm{~g})$, and the other products were low-fat products containing 1.8 to $2.3 \mathrm{~g} / 100 \mathrm{~g}$.

\section{Sensory Analysis}

The sensory profiles of the products were created by quantitative descriptive analysis (QDA) (Akalin et al., 2012). Twenty-three volunteers were recruited from among the students at the Department of Food Science and Technology of the State University of Londrina, Brazil, and their sensory acuity was assessed by recognition tests of basic tastes and odors (Meilgaard et al., 2006).

The descriptive terminology of the products was created by selected panelists using the network method described by Moskowitz (1983). The descriptors (attributes), definitions, and reference samples developed by the sensory panel are shown in Table 3 . The evaluation sheet was prepared in consensus and consisted of 9-cm nonstructured scales, anchored at the extremes by "absent" (anchored at 0) or "weak" (anchored at 0.5 $\mathrm{cm})$ to the left and "intense," "a lot," or "strong" to the right (anchored at $8.5 \mathrm{~cm}$ ), depending on the attribute evaluated (Stone and Sidel, 2004).

After 8 training sessions that lasted $1 \mathrm{~h}$ each, panelist performance was determined by the evaluation of 3 samples (YOG1, WB1, and WB4) in 3 replicates using the evaluation sheet. Data from each panelist were eval- 
uated using a 2-factor ANOVA (samples and replicates) and an $F$-test. In the end, 17 panelists (15 women and 2 men) were considered trained because they were able to discriminate among samples $\left(P\right.$-value of $F_{\text {samples }}<$ $0.5)$, exhibited repeatability during the trials $(P$-value of $F_{\text {repetitions }} \geq 0.05$ ), and reached agreements with the other members of the group (Stone and Sidel, 2004). About $59 \%$ of the panelists were aged 18 to $25 \mathrm{yr}$ old and $41 \%$ were between 25 and $35 \mathrm{yr}$ old.

Analysis of the 8 samples was performed by the trained panel in individual booths in daylight, during which $40 \mathrm{~g}$ of each sample were served in containers coded with random 3-digit numbers, at a temperature of approximately $12^{\circ} \mathrm{C}$, and in a monadic manner. The evaluation was done in 8 sessions with 3 samples, randomly selected, and presented in a random order. The evaluation sheet developed during the training sessions was used. The panelists were not reimbursed for their time and the evaluations were done by all panelists on the same days.

The 74 participants in the liking test were recruited based on their availability to participate in the test and if they were consumers of yogurt and whey beverages. They were students and staff of the State University of Londrina, and the panel comprised $70 \%$ women and $30 \%$ men. Among the judges, $70.3 \%$ were 18 to $25 \mathrm{yr}$

Table 3. Attributes, definitions and reference samples developed by consensus by the sensory panel

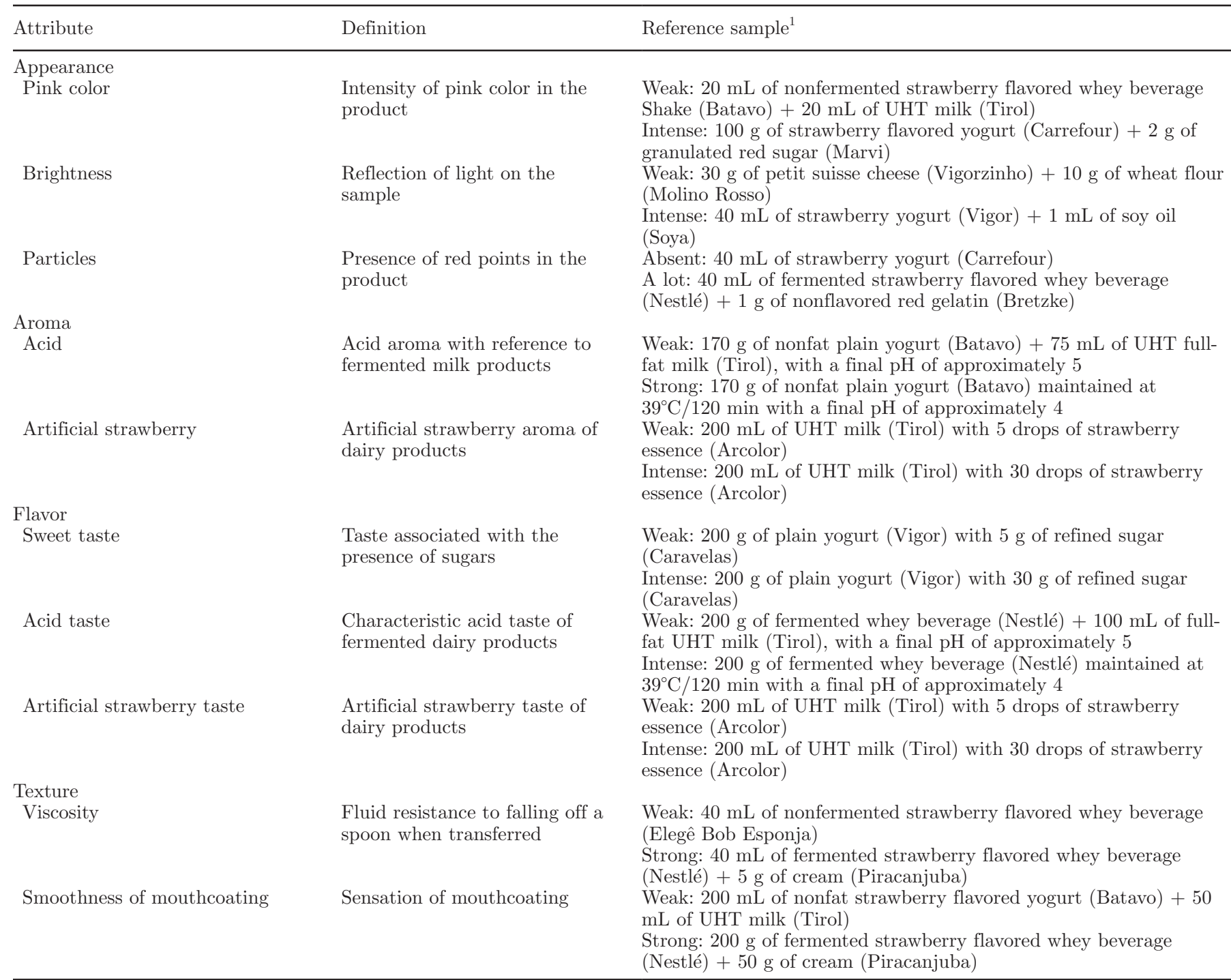

${ }^{1}$ Batavo products (Batavo, São Paulo, Brazil); UHT milk (Tirol, Ponta Grossa, Brazil); strawberry flavor yogurt (Carrefour, São Paulo, Brazil); granulated red sugar (Marvi, Ourinhos, Brazil); Vigor products (Vigor SA, São Paulo, Brazil); wheat flour (Molino Rosso, Pinhais, Brazil); soy oil (Soya, São Paulo, Brazil); Nestlé products (Nestlé, Araçatuba, Brazil); red gelatin (Bretzke, Jaraguá do Sul, Brazil); whey beverage Elegê Bob Esponja (Elegê, Carambei, Brazil); cream (Piracanjuba, Bela Vista de Goias, Brazil); strawberry essence (Arcolor, São Lourenço, Brazil); refined sugar (Caravelas, Ariranha, Brazil). 
old, $24.3 \%$ were 25 to 35 yr old, $4 \%$ were 35 to $50 \mathrm{yr}$ old, and $1.4 \%$ was over 50 .

Two evaluation sessions were conducted with 4 different samples each, and the samples were randomly selected and served in random order to the same 74 participants. The samples (40 g) were presented monadically and in sequence inside containers coded with random 3-digit numbers, at a temperature of approximately $12^{\circ} \mathrm{C}$, under white light. To evaluate overall liking, a structured hedonic scale of 9 points $(9=$ liked very much; $5=$ neither liked nor disliked, and $1=$ disliked very much) was used (Cruz et al., 2012; Morais et al., 2014).

\section{Statistical Analysis}

The experimental data of QDA were submitted to a 2-way ANOVA (samples and panelists) with interaction. When the $F$-value of the sample $\times$ panelist interaction was significant, the value of $F_{\text {sample }}$ was recalculated considering the mean square interaction as the denominator (Bayarri et al., 2011). The differences between the samples were determined by Tukey's test $(P \leq 0.05)$. For liking, the data were submitted to a 2-way ANOVA (samples and panelists), an $F$-test and a Tukey test for comparison of means $(P \leq 0.05)$. Principal component analysis was performed on the average data of each attribute raised in the descriptive test, whereas partial least squares regression was used to correlate the descriptive data with the liking data (Cadena et al., 2012).

External preference mapping (PREFMAP) was obtained using the regression of hedonic values for consumer data against the first 2 dimensions of the sample sensory profile, D1 and D2 (Gaze et al., 2015). A reverse regression was conducted to determine the optimal product profile (Dooley et al., 2010). The coordinates of a point located at a region of greater liking by consumers were used as an independent variable, and the intensity of descriptive attributes (QDA) were used as dependent variables, yielding the attribute equations. A sensory profile of the optimal product was obtained using the coordinates of the optimum point (PREFMAP) in the resulting equations (MacFie, 2007). Statistical analyses were conducted in SAS software (version 9.1.3; SAS Institute Inc., Cary, NC) and XLSTAT for Windows (2013 version; Addinsoft, New York, NY).

\section{RESULTS AND DISCUSSION}

The first 3 principal components were used in interpreting the results, because they had eigenvalues $>1$, according to the Kaiser criterion (Bayarri et al., 2011).
After the factors were orthogonally rotated by following the Varimax transformation with the Kaiser normalization method (Bonany et al., 2014), the first principal component (D1) explained 53\% of the variability contained in the original variables, and the second (D2) and third (D3) components explained 24\% and 20\%, respectively, totaling $97 \%$.

A sensory profile map of the yogurts and whey beverages evaluated is shown in Figure 1. The attributes were considered important in a principal component when its correlation with the axis was greater than 0.7 (absolute values). Dimension 1 was represented by acid aroma and acid taste attributes in the positive part of the axis and artificial strawberry taste and aroma and sweet taste in the negative part of the axis; D2 was positively correlated with the viscosity and smoothness of mouthcoating; and D3 was represented by the attributes color and brightness (positive side of the axis). Therefore, D1 represents the aroma and flavor attributes, D2 represents the texture attributes, and D3 represents the appearance attributes.

Dimension 1 separated the products by fermentation process; the right and center positions show the fermented products (YOG1, YOG2, YOG3, YOG4, WB3, and WB4) and the left position shows the nonfermented products (WB1 and WB2). Additionally, addition of whey grouped the products, with yogurts with no whey (YOG1 and YOG3) on the right side and yogurts with whey (in a form of concentrate or liquid; YOG2 and YOG4), fermented whey beverages (WB3 and WB4) and nonfermented whey beverages (WB1 and WB2) in the center and left side.

Dimension 2 separated the fermented products based on their fat contents, with nonfat yogurts located below the axis (YOG1 and YOG3) and low-fat yogurts and whey beverages above the axis (YOG2, YOG4, WB3, and WB4). Finally, D3 separated the products based on their coloring, with the products with artificial coloring, WB3 (Red Ponceau and brilliant blue) and YOG4 (carmine, Bordeaux red and Red Ponceau), being above the axis, and the products with natural coloring (carmine; WB1, WB4, YOG2, and YOG3) being below the axis. However, the separation was not complete in that 2 products that contained carmine coloring were also positioned above the axis (WB2 and YOG1). Therefore, fermentation process, whey addition, fat content, and coloring type are important parameters for yogurts and whey beverages.

The mean intensity values for the sensory attributes are shown in Table 4. The NFWB (WB1 and WB2) were less acidic (aroma and taste) and less viscous $(P \leq$ $0.05)$ than the yogurts and fermented whey beverages (WB3 and WB4). The NFWB also had lower smoothness of mouthcoating than the yogurts and whey bever- 
ages, with exception of YOG3. In addition, they had a more intense sweet taste and artificial strawberry aroma $(P \leq 0.05)$. The lower acidity of the NFWB (aroma and taste) is related to the fact that no fermentation process occurred, with the consequent accumulation of lactic acid, as expected.

The fermentation process may also explain the viscosity and smoothness of mouthcoating of the products, ir-
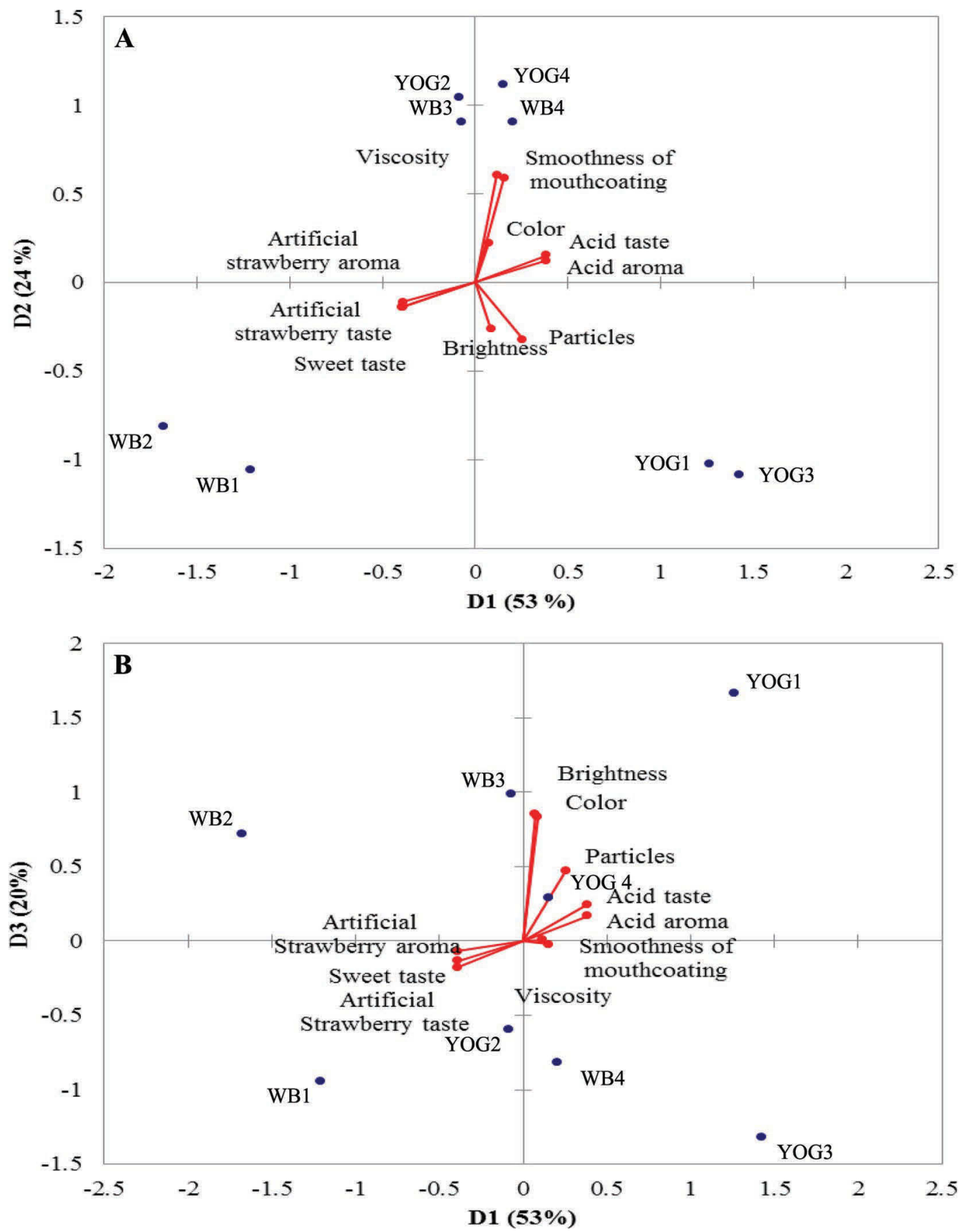

Figure 1. Principal component analysis after varimax transformation (D): attributes (vectors) and yogurts and whey beverages (circles). (A) Dimension (D) 1 versus D2; (B) D1 versus D3. Samples: YOG1 and YOG3 = nonfat yogurt; YOG2 and YOG4 = low-fat yogurt; WB1 = full-fat nonfermented whey beverage, WB2 = low-fat nonfermented whey beverage, WB3 and WB4 = low-fat fermented whey beverage. Color version available online. 
respective of their fat content. Casein is destabilized by the production of lactic acid during milk fermentation, and aggregation occurs at $\mathrm{pH} 4.6$ to 4.7 , forming a 3 -dimensional gel, which is responsible for the viscosity of fermented products (Pereira et al., 2006). Furthermore, production of exopolysaccharide by the microorganisms of the lactic culture also plays an important role in the viscosity and texture of these products (Varnam and Sutherland, 1994). The viscosity of yogurt has a direct influence on the smoothness of mouthcoating of products, and more viscous products are generally considered creamier (Kip et al., 2006). Thus, the NFWB were less viscous and had lower smoothness of mouthcoating than did the yogurts and fermented whey beverages.

The greater intensity of the sweetness and artificial strawberry aroma in NFWB could be related to the higher lactose content or the lower acidity of these products (Table 2). Whey contains a considerable amount of lactose, a disaccharide that can contribute to an increased intensity of the sweet taste of whey beverages (Gallardo-Escamilla et al., 2007). In fact, the NFWB (WB1 and WB2) presented the highest lactose content (Table 2) and, consequently, the highest sweetness, followed by the fermented whey beverages (WB3 and WB4) and the yogurt with WPC (YOG2). The yogurts with no whey (YOG1 and YOG3) had the lowest sweetness (not differing from YOG4). In addition, the acidity in fermented milk products can mask the perception of other attributes related to taste, and therefore, perception of a sweet taste can be greater in nonfermented than in fermented products (Ott et al., 2000).
The low-fat fermented products (YOG2, YOG4, WB3, and WB4), all with added whey or WPC, differed $(P \leq 0.05)$ only slightly in pink color, viscosity, and smoothness of mouthcoating attributes, with WB3 being less viscous and having lower smoothness of mouthcoating than YOG2. The products were similar $(P>$ $0.05)$ in the other parameters evaluated. These results indicate that yogurts with whey or WPC addition and fermented whey beverages have similar sensory profiles.

When comparing the yogurts, we verified that products with lower fat contents (nonfat, YOG1, and YOG3) were characterized as being more acidic (aroma and taste) and less sweet, less viscous, and with lower smoothness of mouthcoating than low-fat yogurt YOG2 $(P \leq 0.05)$. For YOG4, differences $(P$ $\leq 0.05)$ were observed only in viscosity and smoothness of mouthcoating. In fact, the products exhibited differences in the acidity $(\mathrm{pH}$ and titratable acidity; Table 2). Yogurts with higher fat contents have higher viscosity and smoothness of mouthcoating than products with reduced fat content (Guggisberg et al., 2009; Pimentel et al., 2013), because fat globules interact with casein micelles and participate in the formation of a protein gel, providing the oral tactile sensation of full-fat products (smoothness of mouthcoating; Pereira et al., 2006). Furthermore, the presence of fat results in a more agglomerate gel with a closed microstructure, resulting in a cohesive protein network and thus a more viscous product (Pereira et al., 2006). For the NFWB WB1 and WB2, fat content did not affect $(P>0.05)$ the evaluated attributes. Therefore, the fermentation process and milk fat have a greater influence on the

Table 4. The mean intensity $( \pm \mathrm{SD})$ of sensory attributes for yogurts and whey beverages ${ }^{1}$

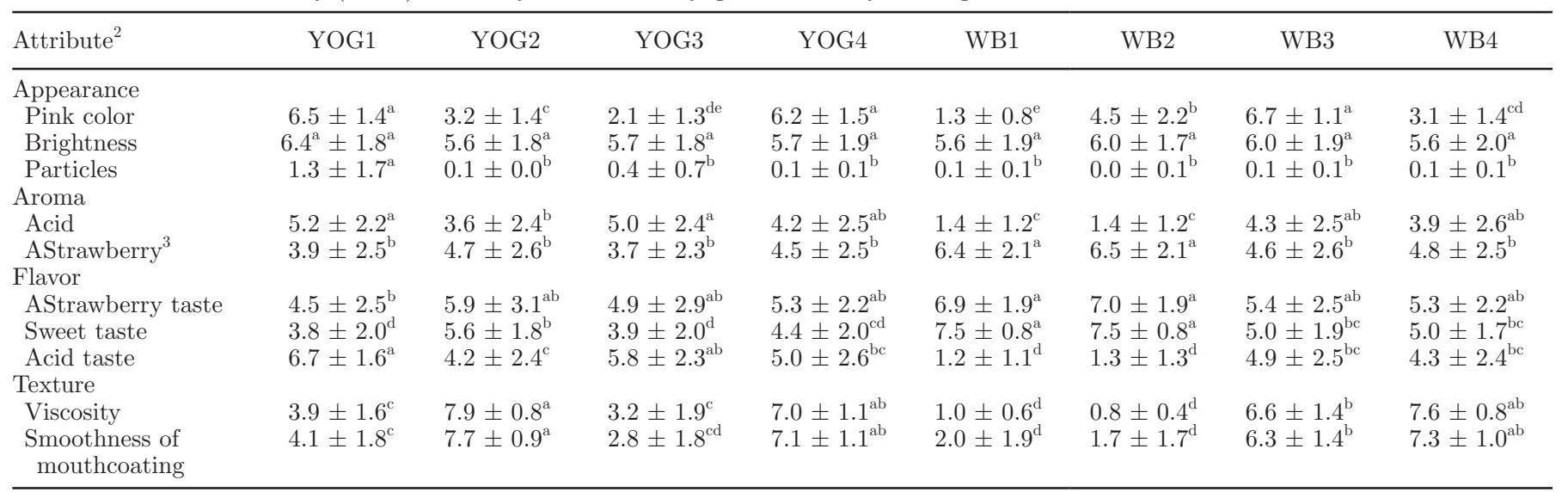

\footnotetext{
${ }^{\mathrm{a} e}$ Means in the same row followed by different letters indicate significant differences $(P \leq 0.05)$ between samples for the same sensory attribute. ${ }^{1}$ Samples: YOG1 and YOG3 = nonfat yogurt; YOG2 and YOG4 = low-fat yogurt; WB1 = full-fat nonfermented whey beverage, WB2 = low-fat nonfermented whey beverage, WB3 and WB4 $=$ low-fat fermented whey beverage $(\mathrm{n}=51)$.

${ }^{2}$ Sensory attributes were scored on a scale of $9 \mathrm{~cm}$ : $0=$ absent, $0.5=$ weak and $8.5=$ intense or strong depending on the attribute; see Table 3 for attribute definitions.

${ }^{3}$ Artificial strawberry.
} 
aroma, flavor, and texture of dairy products, which more effectively influenced their viscosity and smoothness of mouthcoating.

Products YOG1, YOG4, and WB3 had a higher $(P \leq$ $0.05)$ pink color intensity than the other products. This result may be related to the colorings used in production (Red Ponceau, carmine, and Bordeaux-5 in YOG4, and Ponceau Red and brilliant blue in WB3). In the case of YOG1 (colored with carmine), a larger amount of pulp or larger chunks may have been used, which could have been perceived by the panelists as having a higher color intensity.

The NFWB WB1 had the lowest intensity of pink color, which did not differ $(P>0.05)$ from that of YOG3 yogurt, which could be related to the presence of cream as an ingredient and the fact that the strawberries were not added in the form of pulp, as in the remaining products (Table 1). For YOG3, the presence of sweeteners (aspartame and sodium cyclamate) may have contributed to the attenuation of the color (Table 1). Sucrose products usually have a more intense coloration because of the Maillard reaction, and sweeteners do not participate in these reactions (Jain et al., 2013). The differences in pink color could also be related to the concentration of coloring in the product and the pink color quality, which varies depending on the coloring used. All yogurts and whey beverages (fermented or not) showed a similar brightness intensity $(P>0.05)$.

Table 5 shows the results of the consumer test. The overall liking of the products ranged between 4.9 and 7.9 points on a scale of 9 , indicating that consumer product liking was between "neither liked nor disliked" and "liked moderately." The low-fat yogurts YOG2 and YOG4 and fermented whey beverages WB3 and

Table 5. The overall liking (means \pm SD) of yogurts and whey beverages $^{1}$

\begin{tabular}{lc}
\hline Sample & Overall liking $^{2}$ \\
\hline YOG1 & $6.7 \pm 1.9^{\mathrm{b}}$ \\
YOG2 & $7.9 \pm 1.1^{\mathrm{a}}$ \\
YOG3 & $5.5 \pm 2.1^{\mathrm{c}}$ \\
YOG4 & $7.2 \pm 1.2^{\mathrm{ab}}$ \\
WB1 & $4.9 \pm 2.1^{\mathrm{c}}$ \\
WB2 & $5.0 \pm 2.4^{\mathrm{c}}$ \\
WB3 & $7.5 \pm 1.4^{\mathrm{ab}}$ \\
WB4 & $7.2 \pm 1.6^{\mathrm{ab}}$ \\
\hline
\end{tabular}

${ }^{\mathrm{a}-\mathrm{c}}$ Mean values in the same column followed by different letters indicate significant differences $(P \leq 0.05)$.

${ }^{1}$ Samples: YOG1 and YOG3 $=$ nonfat yogurt; YOG2 and YOG4 $=$ low-fat yogurt; WB1 = full-fat nonfermented whey beverage, WB2 = low-fat nonfermented whey beverage, WB3 and WB4 = low-fat fermented whey beverage $(\mathrm{n}=74)$.

${ }^{2}$ Hedonic scale: 1 = disliked very much, $5=$ neither liked nor disliked; $9=$ liked very much.
WB4 were the most liked products by the consumers (hedonic values between 7.2 and $7.9 ; P \leq 0.05$ ). The nonfat yogurt YOG1 was only less liked than the lowfat yogurt YOG2, and WB1, WB2, and YOG3 had the lowest liking scores (an average of 5.2).

The lowest liking scores of NFWB WB1 and WB2 could be primarily related to the lower viscosity and smoothness of mouthcoating. Nonfermented whey beverages have little oral tactile sensation and are more liquid than fermented milks (Gallardo-Escamilla et al., 2007; Castro et al., 2013) because of the low solids content (approximately 6\%) of whey and absence of fermentation process, as noted by consumers. The lowest liking score of yogurt YOG3 could be related to the fact that this product was "light" and sweetened with sweeteners (sodium cyclamate and aspartame), whereas the other evaluated products contained sucrose. The light yogurt probably had a slightly bitter or metallic aftertaste related to the sweeteners that was not detected by the trained panel but decreased the consumer liking of the product. Similar results were reported by other authors for strawberry yogurts (King et al., 2003; Moraes and Bollini, 2010; Reis et al., 2011).

The similar liking scores of nonfat yogurt, YOG1, with other low-fat products (except YOG2) can be explained by the use of thickeners and stabilizers (gelatin and modified starch; Table 1), which also acted effectively as fat substitutes, making the nonfat product as liked as the low-fat product (Isleten and KaragulYuceer, 2008). These components have the ability to increase the viscosity of the products, and when combined, they influence the oral sensation of fat, improving the smoothness of mouthcoating of the product and enhancing consumer acceptability (Gallardo-Escamilla et al., 2007).

The low-fat fermented whey beverages WB3 and WB4 with reconstituted whey were as accepted as yogurts YOG2 and YOG4, with WPC and liquid whey, respectively. This result is quite interesting because yogurt is considered a higher-quality product and has a higher price, and because the use of liquid or reconstituted whey (as a byproduct of the cheesemaking industry) can reduce the cost of production for fermented products (Almeida et al., 2009). No major changes in the chemical composition of fermented whey beverages were found when compared with yogurts with no whey addition (Table 2).

The results of the consumer tests indicate that yogurts and fermented whey beverages had good consumer liking, and it is important to use fat substitutes in low- or nonfat products. However, NFWB and "light" yogurt did not demonstrate satisfactory liking scores by consumers. 


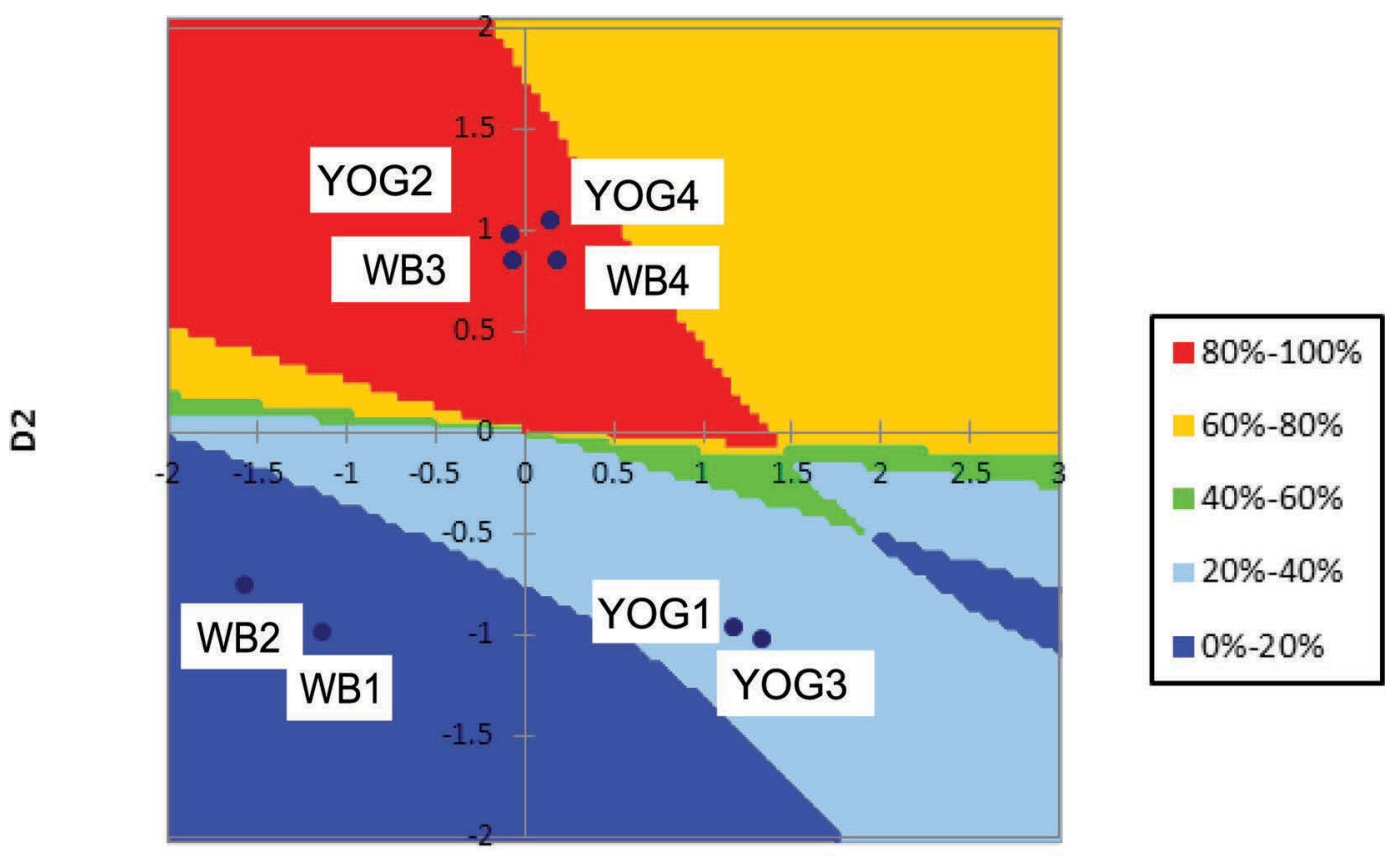

D1

Figure 2. External preference map for yogurt and whey beverages. Samples: YOG1 and YOG3 = nonfat yogurt; YOG2 and YOG4 = low-fat yogurt; WB1 = full-fat nonfermented whey beverage, WB2 = low-fat nonfermented whey beverage, WB3 and WB4 = low-fat fermented whey beverage. Color version available online.

The partial least squares regression was used to determine the sensory attributes that are important in the overall liking of yogurts and whey beverages by consumers. A model of 2 components was obtained, in which the regression explained $91.1 \%$ of the mean liking values ( $\mathrm{Y}$ data) and $82.8 \%$ of the average values for sensory attributes (X data), which were reported with a cumulated $\mathrm{Q}^{2}$ equal to 0.764 , indicating a satisfactory predictive quality of the model.

The standardized coefficients for the sensory attributes were considered significant when the importance of the variable in the projection (VIP) was greater than or equal to 0.8 (Bayarri et al., 2011) and their positive or negative influence for the consumer liking was observed by the numerical value (positive or negative). Attributes with higher numerical values of the standardized coefficient are more important for consumer liking, either positively or negatively (Cadena et al., 2012). In addition, if the standard deviation crosses the $\mathrm{y}$-axis, the influence of the attribute cannot be considered with a $95 \%$ confidence interval (Cadena et al., 2013). Thus, viscosity and smoothness of mouthcoating are attributes that contribute to positively to consumer liking of yogurts and whey beverages. In fact, Soukoulis et al. (2010) state that texture attributes such as smoothness of mouthcoating and viscosity are characteristics of prime importance for the acceptance of semisolid milk products by consumers.

Thus, to increase the acceptability of NFWB by consumers, the viscosity and smoothness of mouthcoating of the products should be improved. Although these products contained added stabilizers and thickeners (xanthan gum, modified starch, carboxymethylcellulose, carrageenan, and maltodextrin; Table 1), these components were not effective in these parameters.

The external preference map for the yogurts and whey beverages evaluated in this study is shown in Figure 2, allowing identification of the map area where the largest number of consumers would be satisfied and, consequently, helping to interpret the drivers. The lowfat yogurts, YOG2 and YOG4, and the fermented whey beverages, WB3 and WB4, were located in the region in which 80 to $100 \%$ of the consumers would be satisfied with the products, and these were the products with greatest consumer liking (Table 5).

The ideal product was characterized by higher levels of brightness, artificial strawberry taste, sweet taste, and artificial strawberry aroma (5.84, 5.82, 5.66, and 5.12 , respectively); intermediate values for smoothness of mouthcoating, color, and viscosity $(4.40,4.26$, and 
4.13, respectively); and a low intensity of acid taste, acid aroma and particulate matter $(3.77,3.32$, and 0.25 , respectively).

From the formulation point of view, this finding implies the preferred use of lactic cultures with low postacidification capacity and moderate exopolysaccharide production capacity, in addition to an incentive to use sweeteners to provide the same degree of sweet taste, without the problems of obesity associated with excessive intake of sucrose. In addition, unlike recent studies in which a negative perception was associated with the use of chemical additives in foods, consumers in the current study did not consider the use of natural ingredients, such as fruit pulp, to be essential for designing the sensory characteristics of the ideal product, because the ideal product should have high levels of artificial strawberry taste and aroma. Finally, the acquisition of fruit preparations with suspended particles is not advised, and it is preferable to use liquid preparations.

\section{CONCLUSIONS}

In conclusion, liquid or reconstituted whey can be used in the manufacture of fermented whey beverages without substantial changes in the sensory attributes and liking of the products compared with yogurts. Furthermore, the use of fat replacers in low-fat yogurt has advantages in product liking, thus making nonfat products equally liked to low-fat products. Viscosity and smoothness of mouthcoating contribute positively to consumer liking of yogurts and whey beverages. The ideal product is characterized by the highest levels of brightness, artificial strawberry taste, sweet taste, and artificial strawberry aroma; intermediate values of smoothness of mouthcoating, viscosity, and pink color and a low acid taste, acid aroma, and particulate matter. These results may be helpful to optimize formulations and will immediately yield optimized products from a sensory point of view, with high potential success in consumer marketing. Further research should evaluate pilot-plant prototypes and confirm drivers of liking with larger groups of consumers.

\section{ACKNOWLEDGMENTS}

The authors thank the National Council for Scientific and Technological Development $(\mathrm{CNPq})$ for the financial support.

\section{REFERENCES}

Akalın, A. S., G. Unal, N. Dinkci, and A. A. Hayaloglu. 2012. Microstructural, textural, and sensory characteristics of probiotic yogurts fortified with sodium calcium caseinate or whey protein concentrate. J. Dairy Sci. 95:3617-3628.
Allgeyer, L. C., M. J. Miller, and S.-Y. Lee. 2010. Sensory and microbiological quality of yogurt drinks with prebiotics and probiotics. J. Dairy Sci. 93:4471-4479.

Almeida, K. E., A. Y. Tamime, and M. N. Oliveira. 2009. Influence of total solids contents of milk whey on the acidifying profile and viability of various lactic acid bacteria. LWT-Food Sci. Technol. 42:672-678.

Ares, G., P. Varela, G. Rado, and A. Giménez. 2011. Identifying ideal products using three different consumer profiling methodologies. Comparison with external preference mapping. Food Qual. Prefer. 22:581-591.

AOAC International. 2004. Official Methods of Analysis. 15th ed. AOAC International, Washington, DC.

Bayarri, S., I. Carbonell, E. Barrios, and E. Costell. 2011. Impact of sensory differences on consumer acceptability of yoghurts and yoghurt-like products. Int. Dairy J. 21:111-118.

Bonany, J., C. Brugger, A. Buehler, J. Carbó, S. Codarin, F. Donati, G. Echeverria, S. Egger, W. Guerra, C. Hilaire, I. Höller, I. Iglesias, K. Jesionkowska, D. Konopacka, D. Krucznska, A. Martinelli, C. Petiot, S. Sansavini, R. Stehr, and F.S. Schoorl. 2014. Preference mapping of apple varieties in Europe. Food Qual. Pref. $32(\mathrm{C}): 317-329$.

Boynton, R. D., and A. M. Novakovic. 2014. Industry evaluations of the status and prospects for the burgeoning New York Greek-style Yogurt Industry. Accessed Feb. 14, 2016. http://ageconsearch. umn.edu/bitstream/186953/2/Cornell-Dyson-rb1401.pdf.

Brasil. 2005. Instrução Normativa no. 16, de 23 de agosto de 2005. Aprova o Regulamento Técnico de Identidade e Qualidade de Bebida Láctea. Diário Oficial da República Federativa do Brasil, Brasília, Brazil.

Brasil. 2007. Instrução Normativa no. 46, de 23 de outubro de 2007. Aprova o Regulamento Técnico de Identidade e Qualidade de Leites Fermentados. Diário Oficial da República Federativa do Brasil, Brasília, Brazil.

Cadena, R. S., A. G. Cruz, J. A. F. Faria, and H. M. A. Bolini. 2012. Reduced fat and sugar vanilla ice creams: Sensory profiling and external preference mapping. J. Dairy Sci. 95:4842-4850.

Cadena, R. S., A. G. Cruz, R. R. Netto, W. F. Castro, J. A. F. Faria, and H. M. A. Bolini. 2013. Sensory profile and physicochemical characteristics of mango nectar sweetened with high intensity sweeteners throughout storage time. Food Res. Int. 54:1670-1679.

Cassell, D. 2014. 2014 Flavor Trends: Yogurt's fruitful union. Accessed Feb. 14, 2016. http://www.foodprocessing.com/articles/2014/ flavor-trends-yogurt/.

Castro, W. F., A. G. Cruz, M. S. Bisinotto, L. M. R. Guerreiro, J. A. F. Faria, H. M. A. Bolini, R. L. Cunha, and R. Deliza. 2013. Development of probiotic dairy beverages: Rheological properties and application of mathematical models in sensory evaluation. J. Dairy Sci. 96:16-25.

Cruz, A. G., R. S. Cadena, W. F. Castro, E. A. Esmerino, J. B. Rodrigues, L. Gaze, J. A. F. Faria, M. Q. Freitas, R. Deliza, and H. M. A. Bolini. 2013. Consumer perception of probiotic yogurt: Performance of check all that apply (CATA), projective mapping, sorting and intensity scale. Food Res. Int. 54:601-610.

Cruz, A. G., R. S. Cadena, J. A. F. Faria, H. M. A. Bolini, C. Dantas, M. M. C. Ferreira, and R. Deliza. 2012. PARAFAC: Adjustment for modeling consumer study covering probiotic and conventional yogurt. Food Res. Int. 45:211-215.

Dooley, L., Y.-S. Lee, and J.-F. Meullenet. 2010. The application of check-all-that-apply (CATA) consumer profiling to preference mapping of vanilla ice cream and its comparison to classical external preference mapping. Food Qual. Prefer. 21:394-401.

Esmerino, E. A., A. G. Cruz, E. P. R. Pereira, J. B. Rodrigues, J. A F. Faria, and H. M. A. Bolini. 2013. The influence of sweeteners in probiotic Petit Suisse cheese in concentrations equivalent to that of sucrose. J. Dairy Sci. 96:5512-5521.

Gallardo-Escamilla, F. J., A. L. Kelly, and C. M. Delahunty. 2007. Mouthfeel and flavour of fermented whey with added hydrocolloids. Int. Dairy J. 17:308-315.

Gaze, L. V., B. R. Oliveira, L. L. Ferrao, D. Granato, R. N. Cavalcanti, C. A. Conte Júnior, A. G. Cruz, and M. Q. Freitas. 2015. 
Preference mapping of dulce de leche commercialized in Brazilian markets. J. Dairy Sci. 98:1443-1454.

Gomes, J. J. L, A. M. Duarte, A. S. M. Batista, R. M. F. Figueiredo, E. P. Sousa, E. L. Souza, and R. Queiroga. 2013. Physicochemical and sensory properties of fermented dairy beverages made with goat's milk, cow's milk and a mixture of the two milks. LWT-Food Sci. Technol. 54:18-24.

Guggisberg, D., J. Cuthbert-Steven, P. Piccinali, U. Butikofer, and P. Eberhard. 2009. Rheological, microstructural and sensory characterization of low-fat and whole milk set yoghurt as influenced by inulin addition. Int. Dairy J. 19:107-115.

Guven, M., K. Yasar, O. B. Karaca, and A. A. Hayaloglu. 2005. The effect of inulin as a fat replacer on the quality of set-type low-fat yogurt manufacture. Int. J. Dairy Technol. 58:180-184.

Hugunin, A. 2009. U.S. whey ingredients in yogurt and yogurt beverages. US Dairy Export Council, Arlington, VA.

Isleten, M., and Y. Karagul-Yuceer. 2008. Effects of functional dairybased proteins on nonfat yogurt quality. J. Food Qual. 31:265-280.

Jain, S., R. Gupta, and S. Jain. 2013. Development of low cost nutritional beverage from whey. J. Environ. Sci. Toxicol. Food Technol. 5:73-88.

King, B. M., P. Arents, and C. A. A. Duineveld. 2003. A comparison of aspartame and sucrose with respect to carryover effects in yogurt. Food Qual. Prefer. 14:75-81.

Kip, P., D. Meyer, and R. H. Jellema. 2006. Inulins improve sensoric and textural properties of low-fat yoghurts. Int. Dairy J. 16:1098-1103.

Legarová, V., and L. Kourimská. 2010. Sensory quality evaluation of whey-based beverages. Mljekarstvo 60:280-287.

Lollo, P. C. B., C. S. Moura, P. N. Morato, A. G. Cruz, W. F. Castro, C. B. Betim, L. Nisishima, J. A. F. Faria, M. Maróstica Junior, C. O. Fernandes, and J. Amaya-Farfán. 2013. Probiotic yogurt offers higher immune-protection than probiotic whey beverage. Food Res. Int. 54:118-124.

Lovely, C., and J.-F. Meullenet. 2009. Comparison of preference mapping techniques for the optimization of strawberry yogurt. J. Sens. Stud. 24:457-478.

MacFie, H. 2007. Preference mapping and food product development. Pages 551-592 in Consumer-Led Food Product Development. H. MacFie, ed. Woodhead Publishing Ltd./CRC Press, Boca Raton, FL.

Meilgaard, M., G. V. Civille, and B. T. Carr. 2006. Sensory Evaluation Techniques. 4th ed. CRC Press, Boca Raton, FL.

Moraes, P. C. B. T., and H. M. A. Bollini. 2010. Perfil sensorial de iogurtes comerciais sabor morango nas versões tradicional e light. Braz. J. Food. Technol. 13:112-119

Morais, E. C., A. R. Morais, A. G. Cruz, and H. M. A. Bolini. 2014 Development of chocolate dairy dessert with addition of prebiotics and replacement of sucrose with different high-intensity sweeteners. J. Dairy Sci. 97:2600-2609.

Moskowitz, H. R. 1983. Product Testing and Sensory Evaluation of Food: Marketing and R\&D Approaches. Food and Nutrition Press, Westport, CT

News and Trends. 2011. Bebidas lácteas são consumidas por quase metade dos brasileiros. Food Ingredients Brasil 16:8-13.

Ott, A., A. Hugi, M. Baumgartner, and A. Chaintreau. 2000. Sensory investigation of yoghurt flavor perception: mutual influence of volatiles and acidity. J. Agric. Food Chem. 48:441-450.
Paixão, J. A., J. B. Rodrigues, E. A. Esmerino, A. G. Cruz, and H. M. A. Bolini. 2014. Influence of temperature and fat content on ideal sucrose concentration, sweetening power, and sweetness equivalence of different sweeteners in chocolate milk beverage. J. Dairy Sci. 97:7344-7353.

Pelegrine, D. H. G., and R. L. Carrasqueira. 2008. Aproveitamento do soro do leite nenriquecimento nutricional de bebidas. Braz. J. Food Technol. VII BMCFB:145-151. http://bjft.ital.sp.gov.br/artigos/ especiais/especial_2009_2/v12ne_t0305.pdf.

Pereira, R., L. Matia-Merino, V. Jones, and H. Singh. 2006. Influence of fat on the perceived texture of set acid milk gels: A sensory perspective. Food Hydrocoll. 20:305-313.

Pimentel, T. C., A. G. Cruz, and S. H. Prudencio. 2013. Short communication: Influence of long-chain inulin and Lactobacillus paracasei subspecies paracasei on the sensory profile and acceptance of a traditional yogurt. J. Dairy Sci. 96:6233-6241.

Pimentel, T. C., S. Garcia, and S. H. Prudencio. 2012. Effect of longchain inulin on the texture profile and survival of Lactobacillus paracase $i$ ssp. paracase $i$ in set yoghurts during refrigerated storage. Int. J. Dairy Technol. 65:104-110.

Pinheiro, M. V. S., M. N. Oliveira, A. L. B. Penna, and A. Y. Tamime. 2005. The effect of different sweeteners in low-calorie yogurts-A review. Int. J. Dairy Technol. 58:193-199.

Reis, R. C., V. P. R. Minim, H. M. A. Bolini, B. R. P. Dias, L. A. Minim, and E. B. Ceresino. 2011. Sweetness equivalence of different sweeteners in strawberry-flavored yogurt. J. Food Qual. 34:163-170.

Ribeiro, M. M., V. P. R. Minim, L. A. Minim, A. C. Arruda, E. B. Ceresino, H. C. F. Carneiro, and P. A. Cipriano. 2010. Estudo de mercado de iogurte da cidade de Belo Horizonte/MG. Rev. Ceres $57: 151-156$

Salvador, A., and M. Fiszman. 2004. Textural and sensory characteristics of whole and skimmed flavored set-type yogurt during long storage. J. Dairy Sci. 87:4033-4041.

Silva, A. N., R. C. S. N. Silva, M. A. M. Ferreira, V. P. R. Minim, T. M. T. Costa, and R. Perez. 2013. Performance of hedonic scales in sensory acceptability of strawberry yogurt. Food Qual. Prefer. 30:9-21.

Silvestrini, A. 2013. Iogurte cresce cada vez mais. Supermercado moderno. Accessed Feb. 14, 2016. http://www.sm.com.br/detalhe/ iogurte-cresce-cada-vez-mais.

Soukoulis, C., E. Rontogianni, and C. Tzia. 2010. Contribution of thermal, rheological and physical measurements to the determination of sensorially perceived quality of ice cream containing bulk sweeteners. J. Food Eng. 100:634-641.

Stone, H., and J. Sidel. 2004. Sensory Evaluation Practices. 3rd ed. Academic Press, New York, NY.

Thompson, J. L., K. Lopetcharat, and M. A. Drake. 2007. Preferences for commercial strawberry drinkable yogurts among African American, Caucasian, and Hispanic consumers in the United States. J. Dairy Sci. 90:4974-4987.

Varnam, A. H., and J. P. Sutherland. 1994. Fermented milks. Pages 347-380 in Milk and Milk Products. Chapman and Hall, London, UK. 